\title{
Prognostic and Predictive Impact of MGMT Promoter Methylation Status in High Risk Grade 2 Glioma
}

\section{Waqar Haque ( $\nabla$ waqarh786@gmail.com )}

CHI St Lukes Health https://orcid.org/0000-0002-2910-6082

\section{Caitlyn Teh}

University of Texas at Austin Architecture and Planning Library: The University of Texas at Austin

\section{E. Brian Butler}

Houston Methodist Hospital

\section{Bin S. Teh}

Houston Methodist Hospital

\section{Research Article}

Keywords: National Cancer Database, overall survival

Posted Date: December 28th, 2021

DOI: https://doi.org/10.21203/rs.3.rs-1189797/v1

License: (c) (i) This work is licensed under a Creative Commons Attribution 4.0 International License. Read Full License 


\section{Abstract}

\section{Background}

MGMT promoter methylation has been associated with favorable prognosis and survival outcomes in patients with glioblastoma and grade 3 glioma. However, the effects of promoter methylation of MGMT in patients with grade 2 gliomas have not been established. The purpose of the current study is to evaluate the prognostic impact and predictive values of MGMT methylation in patients with grade 2 glioma.

Methods

The National Cancer Database (NCDB) was queried (2004-2016) for patients with newly diagnosed grade 2 glioma. Demographics and clinical characteristics of these patients were examined. Statistics included Kaplan-Meier overall survival (OS) analysis alongside Cox proportional hazards modeling.

Results

A total of 11,223 patients met the selection criteria; 1,252 patients (11\%) had MGMT testing. Of the patients who had MGMT testing, 58.5\% were MGMT methylated (mMGMT), and $43.5 \%$ were MGMT unmethylated (UMGMT). mMGMT patients had greater median overall survival (77.3 months) than both UMGMT patients (42.6 months) and patients with no MGMT status reported (61.9 months ( $p<0.001$ for both). mMGMT was also associated with improved OS, when compared to patients with UMGMT, for patients receiving adjuvant chemoradiation or adjuvant radiation therapy.

\section{Conclusions}

This is the largest study to date demonstrating both the prognostic and predictive impact of MGMT methylation on patients with grade II glioma. The current results show that mMGMT is a prognostic factor and possibly a predictive biomarker for grade II glioma patients. MGMT methylation status can be used to determine and stratify patients by risk levels, and thus select patients for treatment intensification.

\section{Importance Of Study}

The present study is the largest to date examining the prognostic and predictive significance of MGMT methylation (mMGMT) in patients with grade II glioma. The results suggest that mMGMT is prognostic with increasing overall survival rates for patients with mMGMT compared to UMGMT patients. The results also suggest that mMGMT is predictive as shown by improved overall survival in patients receiving gross total resection, adjuvant chemoradiation or adjuvant radiation therapy, but no difference was observed in patients receiving adjuvant chemotherapy or no adjuvant treatment. 


\section{Introduction}

Gliomas are primary brain tumors and are graded histologically on the basis of nuclear atypia, mitoses, microvascular proliferation (MVP), and/ or necrosis [1]. WHO Grade II Gliomas, also called low grade gliomas (LGG), are characterized by the presence of nuclear atypia, and the absence of mitoses, and necrosis [2]. Patients with LGG have a more favorable prognosis when compared to patients with either Grade III or Grade IV glioma [1], though there is significant heterogeneity in outcome amongst patients with LGG. Investigators have used either young age ( $\geq 40$ years) or subtotal resection [3], as used in RTOG 98-02, or a combination of at least 3 adverse factors include age $\geq 40$ years, preoperative tumor diameter of $\geq 6 \mathrm{~cm}$, bihemispherical tumor, astrocytoma histology, or preoperative neurological function status of $>1$, as used in RTOG 04-24 [4], to define a subset of patients with LGG who may have high risk disease and therefore may qualify for more intense treatment. RTOG 98-02 has established that the use of a combination of chemotherapy and radiation therapy leads to improved overall survival (OS) when compared to patients treated with radiation therapy alone amongst patients with high risk LGG [5]. The NCCN Guidelines also describe high risk patients as those with either a subtotal resection or age $\geq 40$, though it does state that other high- risk factors can include tumor size and neurologic deficits [6].

Molecular factors can also have prognostic importance in determining outcome for patients with glioma, and for this reason the newest WHO criteria for classifying gliomas take into account the genotypic features in addition to the histopathologic features of tumors when classifying them [7]. While patients with WHO Grade 2 Astrocytoma with IDH wild type are treated as high grade gliomas, there are currently no other biomarkers to guide treatment for patients with LGG. Indeed, the only factors currently used to stratify patients with LGG into either high risk or low risk subsets is the aforementioned clinical factors.

The lack of genetic characteristics to guide management for patients with LGG is different than patients with either Grade III or Grade IV gliomas. In patients with Grade IV gliomas, the effectiveness of alkylating chemotherapy agents like temozolomide is hindered by O\-methylguanine-DNA-methyltransferase (MGMT). Methylation of the MGMT promoter inhibits the production of MGMT in cancer cells by regulating enzyme activity, thus allowing temozolomide to be more effective which results in improved clinical outcomes. The improved clinical outcomes amongst patients with MGMT methylation are most established and studied in glioblastoma patients [8-13] and recently evaluated in grade 3 gliomas [1417]. For this reason, the NCCN does recommend different management for patients with or without a methylated MGMT promoter region.

The impact, if any, on MGMT promoter methylation for patients with LGG with less well established. The only study to thus far investigate the clinical impact of MGMT methylation was a retrospective review patients from RTOG 0424 [18]. Amongst the 75 patients with a known MGMT methylation status, the presence of a methylated MGMT promoter was associated with an improved OS, leading the authors to conclude that MGMT promoter methylation could be a prognostic biomarker for patients with LGG amongst patients treated with temozolomide and radiotherapy. However, since this was a small study, these results need further validation. Furthermore, the study did not address whether there was predictive 
value to MGMT promoter methylation. The purpose of the present study was to use the National Cancer Database (NCDB) to further examine the prognostic and predictive benefit of MGMT methylation in patients with grade II gliomas.

\section{Materials And Methods}

The NCDB is a joint project of the Commission on Cancer ( $\mathrm{CoC}$ ) of the American College of Surgeons and the American Cancer Society, which consists of de-identified information regarding tumor characteristics, demographics, and survival for approximately $70 \%$ of the US population [19]. All pertinent cases are reported regularly from $\mathrm{CoC}$-accredited centers and compiled into a unified dataset, which is then validated. The data used in the study were derived from a de-identified NCDB file (2004-2016). The American College of Surgeons and the $\mathrm{CoC}$ have not verified and are neither responsible for the analytic or statistical methodology employed nor the conclusions drawn from these data by the investigators.

\section{Ethics statement}

As all patient information in the NCDB database is de-identified, this study was exempt from institutional review board evaluation.

Inclusion criteria for this study were patients 18 years and older who were diagnosed with World Health Organization (WHO) grade 2 glioma (either oligodendroglioma, oligoastrocytoma, or astrocytoma histology). In order to determine if MGMT methylation could be a prognostic marker, patients who were diagnosed prior to 2010 were excluded from analysis, as the NCDB did not report MGMT methylation status prior to 2010. Only patients with high risk Grade 2 glioma by the RTOG 9802 [3] criteria were included in the present study, which is patients age $\geq 40$ or those with either subtotal resection or biopsy only. Statistics, performed using STATA (version 14, College Station, TX), were two-sided, with a threshold of $p<0.05$ for statistical significance. Multivariable logistic regression modeling determined characteristics predictive for MGMT testing. Survival analysis was performed by the Kaplan-Meier method, and group comparisons done with the log-rank test. Survival was compared between patients with a methylated MGMT promoter (mMGMT), unmethylated MGMT (UMGMT) promoter, and those with no report of MGMT methylation status. Following this, survival rates were compared after stratifying by extent of surgery and, in order to determine the predictive value of MGMT promoter methylation with different adjuvant treatments, survival was compared after stratifying by MGMT methylation status following treatment with chemotherapy, radiation therapy, chemoradiation, or no adjuvant therapy. Overall survival (OS) referred to the interval between the date of diagnosis and the date of death, or censored at last contact. Univariate analysis ascertained factors associated with OS; subsequently, Cox multivariate analysis included variables that were either significant or showed a strong trend to statistical significance on univariate analysis $(p<0.1)$. For the univariate and multivariate analysis, patients with no record of practice type, radiation therapy use, chemotherapy use, and type of surgery performed were excluded. Additionally, in order to account for immortal time bias, patients who survived 3 months after diagnosis 
were excluded from the survival analyses. Multivariable logistic regression modeling determined characteristics predictive for MGMT testing.

\section{Results}

As shown in Figure 1, a total of 11,223 patients met the selection criteria. Table 1 describes the clinical and demographic characteristics of the patients included in the study. While stratifying patients into groups based on their MGMT methylation status and whether or not these patients had MGMT testing. As shown, 9,971 patients ( $89 \%$ ) of the total 11,223 patients did not have MGMT testing. Of patients who underwent MGMT testing, 634 (50.6\%) were mMGMT, and 618 (49.4\%) were uMGMT. MGMT testing was more frequently performed at Academic institutions and in more recent time periods.

Figure 2 displays the overall survival curves (OS) for all patients when stratified by MGMT methylation status. The median OS for patients with mMGMT was 77.3 months and was greater than the median OS for patients with uMGMT (42.6 months, $p<0.001)$ and greater than for patients with no MGMT status reported $(61.9$ months, $p<0.001)$. OS was also greater for patients with no MGMT status reported than for patients with uMGMT $(p<0.001)$.

To determine the predictive significant of MGMT, OS was examined after different types of management (Figure 3). Patients with mMGMT were found to have improved OS than those with uMGMT following gross total resection (Figure 3A, 5 year OS $52.1 \%$ vs $28.8 \%, p<0.001$ ), but not following subtotal resection (Figure 3B, $65.8 \%$ vs $52.7 \%$ ), or biopsy (Figure $3 C$, 5 year OF $53.2 \%$ vs $50.7 \%, p=0.209$ ). Next, OS was compared following different adjuvant management options following any degree of surgery. Improved OS was observed amongst patients with mMGMT following adjuvant chemoradiation (Figure $3 \mathrm{D}, 5$ year OS $39.0 \%$ vs $25.3 \%, \mathrm{p}<0.001$ ) and following adjuvant radiation alone (Figure $3 \mathrm{~F}, 5$ year OS $67.5 \%$ vs $48.4 \%, p=0.032$ ). However, there was no difference in OS between the mMGMT and uMGMT patients amongst patients treated with adjuvant chemotherapy alone (Figure 3E, 5 year OS $73.3 \%$ vs $63.2 \%, p=0.394$ ) or patients receiving no adjuvant treatment (Figure $3 G, 5$ year OS $77.7 \%$ vs $66.0 \%, p=$ $0.350)$.

Cox univariate and multivariate analysis for factors predictive of overall survival are shown in Table 2 . When compared to patients with MMGMT, UMGMT as well an unreported MGMT methylation status were associated with worse OS. Other factors associated with worse OS on both univariate and multivariate analysis included increasing age, a higher number of comorbidities, biopsy only when compared to gross total resection (GTR), as well as oligoastrocytoma and astrocytoma histology when compared to oligodendroglioma histology.

\section{Discussion}

The present study is the largest to date examining the prognostic and predictive status of MGMT for patients with high risk LGG. These results suggest that MGMT is a prognostic biomarker, as amongst all 
patients with high risk LGG, there was a statistically significant improved OS amongst all patients with mMGMT when compared to those with uMGMT. These results also demonstrate that MGMT can be a predictive biomarker, as improved OS was limited to patients treated with treated with adjuvant chemoradiation or adjuvant radiation, but not to patients receiving adjuvant chemotherapy or no adjuvant treatment. Additionally, mMGMT was associated with improved OS amongst patients receiving a gross total resection, but not those receiving subtotal resection or only.

The current findings are in concordance with a review of patients enrolled in RTOG 0424 [4]. In this study, which was a single arm Phase II trial evaluated the efficacy of radiation and Temozolomide chemotherapy in patients with high risk LGG, 75 patients had MGMT status available. Patients with mMGMT were found to have improved OS [18], leading the authors to conclude that MGMT was an independent prognostic biomarker for patients with LGG treated with radiation therapy and temozolomide. The present data also suggests that MGMT mehtylation can be a prognostic biomarker, as patients with mMGMT were found to have improved OS compared to patients with UMGMT amongst all patients irrespective of treatment [20]. However, MGMT may also serve as a predictive biomarker, as there was no observed difference between patients with mMGMT and those with uMGMT amongst patients receiving adjuvant chemotherapy only, or amongst patients receiving no adjuvant treatment.

The stratification of patients with LGG into high risk disease status is currently made on the basis clinical factors such as age, extent of resection, and size of tumor [6]. This is different than in patients with higher grade gliomas, in which biomarkers can be used to guide treatment. MGMT has been shown to be a predictive biomarker for patients with Glioblastoma, particularly with response to Temozolomide chemotherapy [21], and consequently Temozolomide alone is an option for elderly patients with mMGMT Glioblastoma. MGMT promoter methylation has also been shown to be predictive for patients with Grade 3 Glioma, as event free survival (EFS) was shown in one trial to be greater with Temozolomide than radiation therapy amongst mMGMT patients, while the opposite was true in patients with UMGMT [22]. The results from this study similar show the predictive significant of MGMT promoter methylation in the high risk LGG population, as patients with MMGMT were found to have greater OS following chemoradiation or radiation but not following chemotherapy alone. This may suggest that patients with uMGMT can be used to select for high risk LGG patients who may have a worse response to the recommended chemoradiation, and may need treatment intensification in order to improve outcomes. Future trials may also be considered comparing the use of Temozomide chemotherapy alone to radiation therapy amongst patients with mMGMT to determine if this treatment can achieve medical equipoise as has been seen in patients with Grade 3 Glioma or elderly patients with Glioblastoma.

The reasons why mMGMT only was predictive for outcome for patients receiving adjuvant radiation or chemoradiation but not patients receiving adjuvant chemotherapy are unclear. This may be caused by the small number of patients in the present analysis receiving chemotherapy alone, that did not allow for enough statistical power to reveal a difference in outcome. Another possible explanation for this observation may be that the mechanism of treatment resistance by MGMT may be different in LGG when compared to HGG or Glioblastoma, just as it has previously been suggested that the mechanism of 
MGMT related treatment resistance in different in HGG when compared to Glioblastoma [16]. An additional reason may be due to the inability of MGMT methylation status to serve as a predictive biomarker in patients receiving non- Temozolomide chemotherapy.

This study was retrospective and conducted with hospital based data and as such is subject to certain limitations. First, there are variations of the definition of gross total resection or subtotal resection, limited information concerning chemotherapy agents, and a lack of information regarding progression free survival. Additionally, as a retrospective study, there is possible selection bias and imbalance between the cohorts. Third, there is also potential miscoding or under coding of the factor that codes for a record of MGMT, and that the true count of patients tested for MGMT may be higher than the value reported in this study. Fourth, there were a limited number of patients receiving no adjuvant treatment or receiving adjuvant chemotherapy, limiting the ability of this study to make strong conclusions regarding the predictive value of MGMT methylation. Finally, the reasons for a particular treatment, such as adjuvant radiation or adjuvant radiation along with chemotherapy, and are possible to be ascertained.

The results of this study suggest that MGMT promoter methylation in patients with low grade (grade 2) glioma is associated with improved OS compared to non-methylated patients. Furthermore, the improved OS with MGMT promoter methylation may be limited to patients who receive either adjuvant radiation or adjuvant chemoradiation, but not those receiving adjuvant chemotherapy alone. Further studies are recommended to confirm the impact of MGMT methylation amongst patients with LGG, though this study suggests that MGMT promoter methylation does have prognostic value amongst patients with high grade LGG.

\section{Declarations}

Funding: There was no research support for this study.

Data availability statement: The datasets generated during and/or analysed during the current study are not publicly available due to this being the property of the National Cancer Data Base. These data are available from the Committee On Cancer's National Cancer Data Base on reasonable request.

\section{Contribution of authors:}

Waqar Haque: Experimental design, analysis and interpretation of data, writing and revising manuscript

Caitlyn Teh: analysis and interpretation of data, writing and revising manuscript

E. Brian Butler: analysis and interpretation of data, writing and revising manuscript

Bin S. Teh: analysis and interpretation of data, writing and revising manuscript

\section{References}


1. Kros JM (2011) Grading of gliomas: the road from eminence to evidence. J Neuropathol Exp Neurol 70:101-109

2. Kleihues P, Burger PC, Plate KH, Ohgaki H, Cavenee WK (1997) Pathology and genetics of tumours of the nerouvs systemi. International Agency for Research on Cancer, Lyon, France

3. Shaw EG, Wang M, Coons SW et al (2012) Randomized trial of radiation therapy plus procarbazine, lomustine, and vincristine chemotherapy for supratentorial adult low- grade glioma: initial results of RTOG 9802. J Clin Oncol 30:3065-3070

4. Fisher BJHC, Hu C, Macdonald DR et al (2015) Phase II study of temozolomide-based chemoradiation therapy for high-risk low-grade gliomas: preliminary results of Radiation Therapy Oncology Group 0424. Int J Radiat Oncol Biol Phys 91(3):497-504

5. Buckner JC, Shaw EG, Pugh SL et al (2016) Radiation plus Procarbazine, CCNU, and Vincristine in low- grade glioma. New Engl J Med 374:1344-1355

6. National Comprehensive Cancer Network. Central Nervous System Cancers (Version 2.2021) https://www.nccn.org/professionals/physician_gls/pdf/cns. pdf. Accessed October 1, 2021

7. Louis DN, Perry A, Reifenberger G et al (2016) The 2016 World Health Organization classification of tumors of the central nervous system: a summary. Acta Neuropathol 131(6):803-820

8. Hegi ME, Diserens A-C, Gorlia T et al (2005) MGMT Gene Silencing and Benefit from Temozolomide in Glioblastoma. N Engl J Med 352(10):997-1003

9. Stupp R, Mason WP, van den Bent MJ et al (2005) Radiotherapy plus concomitant and adjuvant Temozlomide for Glioblastoma. New Engl J Med 352:987-996

10. Gilbert MR, Wang M, Aldape KD et al (2013) Dose-dense temozolomide for newly diagnosed glioblastoma: a randomized phase III clinical trial. J Clin Oncol 31(32):4085-4091

11. Gilbert MR, Dignam JJ, Armstrong TS et al (2014) A randomized trial of bevacizumab for newly diagnosed glioblastoma. N Engl J Med 370(8):699-708

12. Stupp R, Taillibert S, Kanner A et al (2017) Effect of tumor-treating fields plus maintenance temozolomide vs maintenance temozolomide alone on survival in patients with glioblastoma: a randomized clinical trial. JAMA 318(23):2306

13. Zhao H, Wang S, Song C, Zha Y, Li L (2016) The prognostic value of MGMT promoter status by pyrosequencing assay for glioblastoma patients' survival: a metaanalysis. World J Surg Onc; 14(1)

14. Haque W, Thong E, Andrabi S, Verma V, Butler EB, Teh BS (2021) Prognositc and predictive impact of MGMT promoter methylation in grade 3 gliomas. J Clin Neurosci 85:115-121

15. Gorlia LA T, et al (A hypermethylated phenotype is a better predictor of survival than MGMT methylation in anaplastic oligodendroglial brain tumors: a report from EORT study 26951. Clin Cancer Res 2011);17:7148-55

16. Van gen bent MJ, Dubbink HJ, Sanson M (2009) MGMT promoter methylation is prognostic but not predictive for outcome to adjuvant PCV chemotherapy in anaplastic oligodendroglial tumors: a report from EORTC Brain Tumor Group Study 26951. J Clin Oncol 27(35):5881-5886 
17. Van den Bent MJ, Baumert B, Erridge SC et al (2017) Interim results from the CATNON trial (EORTC study 26053-22054) of treatment with concurrent and adjuvant temozolomide for $1 p / 19 q$ non-codeleted anaplastic glioma: a phase 3 , randomised, open-label intergroup study. The Lancet 390(10103):1645-1653

18. Bell EH, Zhang P, Fisher BJ, Macdonald DR, McElroy JP, Lesser GJ et al (2018) Association of MGMT promoter methylation status with survival outcomes in patients with high-risk glioma treated with radiotherapy and temozolomide: An analysis from the NRG Oncology/RTOG 0424 Trial. JAMA Oncol 4(10):1405-1409

19. Biilimoria KY, Stewart AK, Winchester DP et al (2008) The National Cancer Data Base: A Powerful Initiative to Improve Cancer Care in the United States. Ann Surg Oncol 15(3):683-690

20. Sechidis K, Papangelou K, Metcalfe PD et al (2018) Distinguishing prognostic and predicitive biomarkers: an information theoretic approach. Bioinformatic 34:3365

21. Malmstrom A, Gronberg BH, Marosi C et al (2012) Temozolomide versus standard 6- week radiotherapy versus hypofractionated radiotherapy in patients older than 60 years with glioblastoma: the Nordic randomised, phase 3 trial. Lancet Oncol 13:916-926

22. Wick W, Platten M, Meisner $C$ et al (2012) Temozolomide chemotherapy versus radiotherapy alone for malignant astrocytoma in the elderly: the NOA- 08 randomised, phase 3 trial. Lancet Oncol 13:707-715

23. Legend

\section{Tables}

Table 1. Patient demographic and clinical characteristics. 


\begin{tabular}{|c|c|c|c|c|}
\hline Characteristic & $\begin{array}{l}\text { MGMT } \\
\text { Methylated (n= } \\
634)\end{array}$ & $\begin{array}{l}\text { MGMT Non- } \\
\text { methylated }(n=618)\end{array}$ & $\begin{array}{l}\text { MGMT Not } \\
\text { reported }(n=9971)\end{array}$ & $\begin{array}{l}\mathrm{P} \text { - } \\
\text { value }\end{array}$ \\
\hline \multicolumn{5}{|l|}{ Age } \\
\hline$\leq 40$ & $91(14.4 \%)$ & $119(19.3 \%)$ & 1908 (19.1\%) & 0.001 \\
\hline $40-50$ & 190 (30.0\%) & 156 )25.2\%) & $2756(27.6 \%)$ & \\
\hline $51-65$ & $213(33.6 \%)$ & $218(35.3 \%)$ & $3203(32.1 \%)$ & \\
\hline $66-79$ & $124(19.6 \%)$ & $112(18.1 \%)$ & $1666(16.7 \%)$ & \\
\hline $80+$ & $16(2.5 \%)$ & $13(2.1 \%)$ & $438(4.4 \%)$ & \\
\hline \multicolumn{5}{|l|}{ Sex } \\
\hline Male & $350(55.2 \%)$ & $351(56.8 \%)$ & $5536(55.5 \%)$ & 0.811 \\
\hline Female & $284(44.8 \%)$ & $267(43.2 \%)$ & 4435 (44.5\%) & \\
\hline \multicolumn{5}{|l|}{ Race } \\
\hline White & $576(90.9 \%)$ & $543(87.8 \%)$ & 8857 (88.8\%) & 0.253 \\
\hline African American & $28(4.4 \%)$ & $36(5.8 \%)$ & $612(6.1 \%)$ & \\
\hline Other/ not recorded & $30(4.7 \%)$ & $39(6.2 \%)$ & $502(5.1 \%)$ & \\
\hline \multicolumn{5}{|l|}{$\begin{array}{l}\text { Charlson-Deyo } \\
\text { comorbidity score }\end{array}$} \\
\hline 0 & $516(81.4 \%)$ & $482(78.0 \%)$ & $7883(79.1 \%)$ & 0.168 \\
\hline 1 & $79(12.5 \%)$ & $100(16.2 \%)$ & $1346(13.5 \%)$ & \\
\hline 2 & $31(4.9 \%)$ & $24(3.9 \%)$ & $517(5.2 \%)$ & \\
\hline$\geq 3$ & $8(1.3 \%)$ & $12(1.9 \%)$ & $225(2.3 \%)$ & \\
\hline \multicolumn{5}{|l|}{ Practice type } \\
\hline Academic & $368(58.0 \%)$ & $326(52.8 \%)$ & $4130(41.4 \%)$ & $<0.001$ \\
\hline Non Academic & $175(27.6 \%)$ & $173(28.0 \%)$ & 3933 (39.4\%) & \\
\hline Not recorded & $91(14.4 \%)$ & 119 (19.3\%) & 1908 (19.1\%) & \\
\hline \multicolumn{5}{|l|}{ Insurance status } \\
\hline Medicare & $147(23.2 \%)$ & $135(21.8 \%)$ & $2322(23.3 \%)$ & $<0.001$ \\
\hline Private & $386(60.9 \%)$ & $402(65.1 \%)$ & $5576(55.9 \%)$ & \\
\hline Medicaid & $60(9.5 \%)$ & $45(7.3 \%)$ & 1024 (10.3\%) & \\
\hline Not insured & $20(3.2 \%)$ & $17(2.8 \%)$ & $601(6.0 \%)$ & \\
\hline & & Page 10/16 & & \\
\hline
\end{tabular}




\begin{tabular}{|c|c|c|c|c|}
\hline $\begin{array}{l}\text { Other governemnt/ } \\
\text { not recorded }\end{array}$ & $21(3.3 \%)$ & $19(3.1 \%)$ & $448(4.5 \%)$ & \\
\hline \multicolumn{5}{|l|}{ Surgery type } \\
\hline Biopsy only & $132(20.8 \%)$ & $149(24.1 \%)$ & $2575(25.8 \%)$ & $<0.001$ \\
\hline $\begin{array}{l}\text { Subtotal resection } \\
\text { (STR) }\end{array}$ & $182(28.7 \%)$ & $134(21.7 \%)$ & 2467 (24.7\%) & \\
\hline Gross todal resection & $130(20.5 \%)$ & $101(16.3 \%)$ & $1529(15.3 \%)$ & \\
\hline Surgery NOS & $27(4.3 \%)$ & $30(4.9 \%)$ & $561(5.6 \%)$ & \\
\hline Not reported (NR) & $163(25.7 \%)$ & $204(33.0 \%)$ & $2839(28.5 \%)$ & \\
\hline \multicolumn{5}{|l|}{ Radiation therapy } \\
\hline Yes & 367 (57.9\%) & $386(62.5 \%)$ & $4918(49.3 \%)$ & $<0.001$ \\
\hline No & $264(41.6 \%)$ & $224(36.3 \%)$ & $4946(49.6 \%)$ & \\
\hline Not reported & $3(0.5 \%)$ & $8(1.3 \%)$ & 107 (1.07\%) & \\
\hline \multicolumn{5}{|l|}{ Chemotherapy } \\
\hline Yes & $408(64.4 \%)$ & $366(59.2 \%)$ & $4254(42.7 \%)$ & $<0.001$ \\
\hline No & 197 (31.1\%) & $232(37.5 \%)$ & $5253(52.7 \%)$ & \\
\hline Not reported & $29(4.6 \%)$ & $20(3.2 \%)$ & $464(4.7 \%)$ & \\
\hline \multicolumn{5}{|l|}{ Histology } \\
\hline Oligodendroglioma & $251(39.6 \%)$ & $126(20.4 \%)$ & $3032(30.4 \%)$ & $<0.001$ \\
\hline Oligoastrocytoma & $127(20.0 \%)$ & $125(20.2 \%)$ & $2029(20.4 \%)$ & \\
\hline Astrocytoma & $256(40.4 \%)$ & $367(59.4 \%)$ & $4910(49.2 \%)$ & \\
\hline \multicolumn{5}{|l|}{ Year of diagnosis } \\
\hline 2010 & $36(5.7 \%)$ & $66(10.7 \%)$ & $1608(16.1 \%)$ & $<0.001$ \\
\hline 2011 & $27(4.3 \%)$ & $69(11.2 \%)$ & $1620(16.3 \%)$ & \\
\hline 2012 & $53(8.4 \%)$ & $58(9.4 \%)$ & $1501(15.1 \%)$ & \\
\hline 2013 & $67(10.6 \%)$ & $75(12.1 \%)$ & $1567(15.7 \%)$ & \\
\hline 2014 & $126(19.9 \%)$ & $86(13.9 \%)$ & $1364(13.7 \%)$ & \\
\hline 2015 & $155(24.5 \%)$ & $122(19.7 \%)$ & $1228(12.3 \%)$ & \\
\hline 2016 & $170(26.8 \%)$ & $142(23.0 \%)$ & $1083(10.9 \%)$ & \\
\hline
\end{tabular}

Table 2. Univariate and multivariate analysis for factors predictive of overall survival. 


\begin{tabular}{|c|c|c|c|c|c|c|}
\hline & UVA & & & MVA & & \\
\hline Characteristic & $\begin{array}{l}\text { Hazard } \\
\text { ratio }\end{array}$ & $\begin{array}{l}95 \% \\
\text { confidence } \\
\text { interval }\end{array}$ & $\begin{array}{l}\mathrm{P} \text { - } \\
\text { value }\end{array}$ & $\begin{array}{l}\text { Hazard } \\
\text { ratio }\end{array}$ & $\begin{array}{l}95 \% \\
\text { confidence } \\
\text { interval }\end{array}$ & $\begin{array}{l}\mathrm{P}- \\
\text { value }\end{array}$ \\
\hline \multicolumn{7}{|l|}{$\begin{array}{l}\text { MGMT Methylation } \\
\text { status }\end{array}$} \\
\hline Methylated & \multicolumn{3}{|l|}{$\begin{array}{l}1 \\
\text { (reference) }\end{array}$} & \multicolumn{3}{|c|}{1 (reference) } \\
\hline Unmethylated & 1.679 & $1.352-2.086$ & $<0.001$ & 1.575 & $1.267-1.958$ & $<0.001$ \\
\hline Not reported & 1.47 & $1.233-1.752$ & $<0.001$ & 1.409 & $1.180-1.682$ & $<0.001$ \\
\hline \multicolumn{7}{|l|}{ Age } \\
\hline$\leq 40$ & \multicolumn{3}{|l|}{$\begin{array}{l}1 \\
\text { (reference) }\end{array}$} & \multicolumn{3}{|c|}{1 (reference) } \\
\hline $40-50$ & 1.624 & $1.420-1.859$ & $<0.001$ & 1.628 & $1.410-1.879$ & $<0.001$ \\
\hline $51-65$ & 3.949 & $3.495-4.464$ & $<0.001$ & 3.450 & 3.016- 3.947 & $<0.001$ \\
\hline $66-79$ & 8.851 & $7.802-10.041$ & $<0.001$ & 5.605 & $4.776-6.576$ & $<0.001$ \\
\hline $80+$ & 19.217 & $\begin{array}{l}16.485- \\
22.402\end{array}$ & $<0.001$ & 11.348 & $\begin{array}{l}9.430- \\
13.655\end{array}$ & $<0.001$ \\
\hline \multicolumn{7}{|l|}{ Sex } \\
\hline Male & \multicolumn{3}{|l|}{1 (reference) } & \multicolumn{3}{|c|}{1 (reference) } \\
\hline Female & 0.945 & $0.888-1.005$ & 0.074 & 0.960 & $0.901-1.022$ & 0.198 \\
\hline \multicolumn{7}{|l|}{ Race } \\
\hline White & \multicolumn{3}{|l|}{$\begin{array}{l}1 \\
\text { (reference) }\end{array}$} & \multicolumn{3}{|c|}{1 (reference) } \\
\hline African American & 0.953 & $0.835-1.088$ & 0.479 & 1.074 & $0.940-1.229$ & 0.294 \\
\hline Other/ not recorded & 0.753 & $0.640-0.886$ & 0.001 & 0.900 & $0.764-1.060$ & 0.205 \\
\hline \multicolumn{7}{|l|}{$\begin{array}{l}\text { Charlson-Deyo } \\
\text { comorbidity score }\end{array}$} \\
\hline 0 & \multicolumn{3}{|l|}{$\begin{array}{l}1 \\
\text { (reference) }\end{array}$} & \multicolumn{3}{|c|}{1 (reference) } \\
\hline 1 & 1.672 & $1.540-1.815$ & $<0.001$ & 1.197 & $1.101-1.301$ & $<0.001$ \\
\hline 2 & 2.168 & $1.926-2.442$ & $<0.001$ & 1.514 & $1.342-1.706$ & $<0.001$ \\
\hline$\geq 3$ & 2.731 & $2.288-3.260 \%$ & $<0.001$ & 1.961 & $1.639-2.345$ & $<0.001$ \\
\hline
\end{tabular}




\begin{tabular}{|c|c|c|c|c|c|c|}
\hline \multicolumn{7}{|l|}{ Practice type } \\
\hline \multirow{2}{*}{$\begin{array}{l}\text { Academic } \\
\text { Non Academic }\end{array}$} & \multicolumn{3}{|l|}{$\begin{array}{l}1 \\
\text { (reference) }\end{array}$} & \multicolumn{3}{|c|}{1 (reference) } \\
\hline & 1.443 & 1.353- 1.539 & $<0.001$ & 1.155 & $1.082-1.234$ & $<0.001$ \\
\hline Not recorded & 0.311 & $0.275-0.351$ & $<0.001$ & - & - & - \\
\hline \multicolumn{7}{|l|}{ Insurance status } \\
\hline Medicare & \multicolumn{3}{|l|}{$\begin{array}{l}1 \\
\text { (reference) }\end{array}$} & \multicolumn{3}{|c|}{1 (reference) } \\
\hline Private & 0.262 & $0.245-0.281$ & $<0.001$ & 0.725 & $0.656-0.800$ & $<0.001$ \\
\hline Medicaid & 0.309 & $0.274-0.328$ & $<0.001$ & 0.966 & $0.839-1.112$ & 0.633 \\
\hline Not insured & 0.308 & $0.265-0.357$ & $<0.001$ & 1.000 & $0.844-1.184$ & 0.996 \\
\hline $\begin{array}{l}\text { Other governemnt/ } \\
\text { not recorded }\end{array}$ & 0.387 & $0.330-0.454$ & $<0.001$ & 0.931 & $0.784-1.105$ & 0.413 \\
\hline \multicolumn{7}{|l|}{ Surgery type } \\
\hline Biopsy only & \multicolumn{3}{|l|}{$\begin{array}{l}1 \\
\text { (reference) }\end{array}$} & \multicolumn{3}{|c|}{1 (reference) } \\
\hline $\begin{array}{l}\text { Subtotal resection } \\
\text { (STR) }\end{array}$ & 0.748 & $0.681-0.821$ & $<0.001$ & 0.987 & $0.897-1.985$ & 0.782 \\
\hline Gross todal resection & 0.761 & $0.682-0.848$ & $<0.001$ & 0.739 & $0.661-0.826$ & $<0.001$ \\
\hline Surgery NOS & 1.132 & $0.983-1.303$ & 0.084 & 0.876 & $0.759-1.010$ & 0.068 \\
\hline Not reported (NR) & 1.861 & $1.719-2.016$ & $<0.001$ & 1.167 & $1.076-1.267$ & $<0.001$ \\
\hline \multicolumn{7}{|l|}{ Radiation therapy } \\
\hline Yes & \multicolumn{3}{|l|}{$\begin{array}{l}1 \\
\text { (reference) }\end{array}$} & \multicolumn{3}{|c|}{1 (reference) } \\
\hline No & 0.624 & $0.585-0.665$ & $<0.001$ & 0.866 & $0.802-0.934$ & $<0.001$ \\
\hline Not reported & 0.503 & $0.344-0.734$ & $<0.001$ & 0.605 & $0.407-0.900$ & 0.013 \\
\hline \multicolumn{7}{|l|}{ Chemotherapy } \\
\hline Yes & \multicolumn{3}{|l|}{$\begin{array}{l}1 \\
\text { (reference) }\end{array}$} & \multicolumn{3}{|c|}{1 (reference) } \\
\hline No & 0.786 & $0.738-0.837$ & $<0.001$ & 0.847 & $0.786-0.913$ & $<0.001$ \\
\hline Not reported & 0.625 & $0.523-0.747$ & $<0.001$ & 0.782 & $0.646-0.946$ & 0.012 \\
\hline \multicolumn{7}{|l|}{ Histology } \\
\hline Oligodendroglioma & $\begin{array}{l}1 \\
\text { (reference) }\end{array}$ & & & 1 (refer & ce) & \\
\hline
\end{tabular}




\section{Figures}

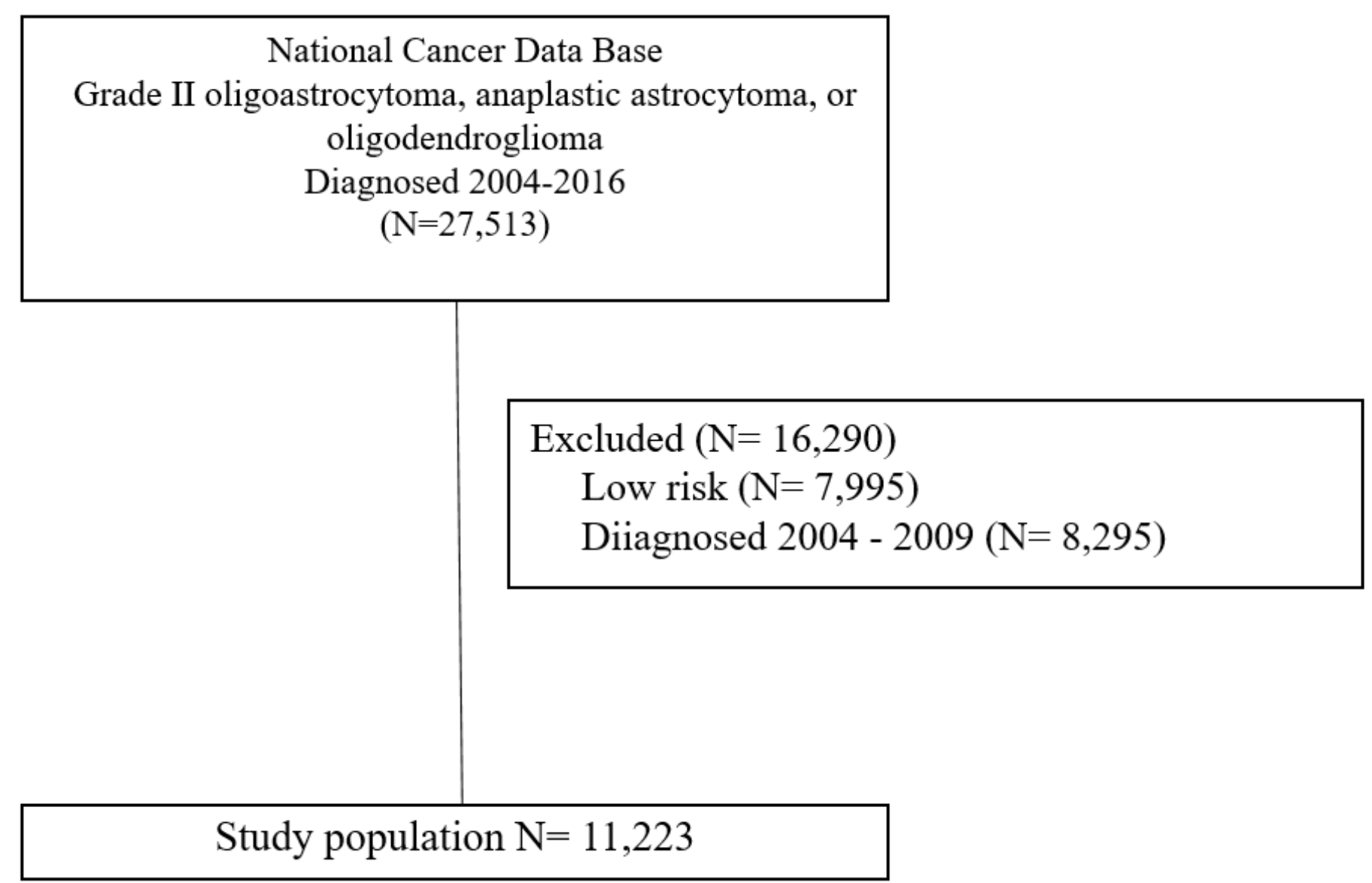

Figure 1

Patient selection diagram. 


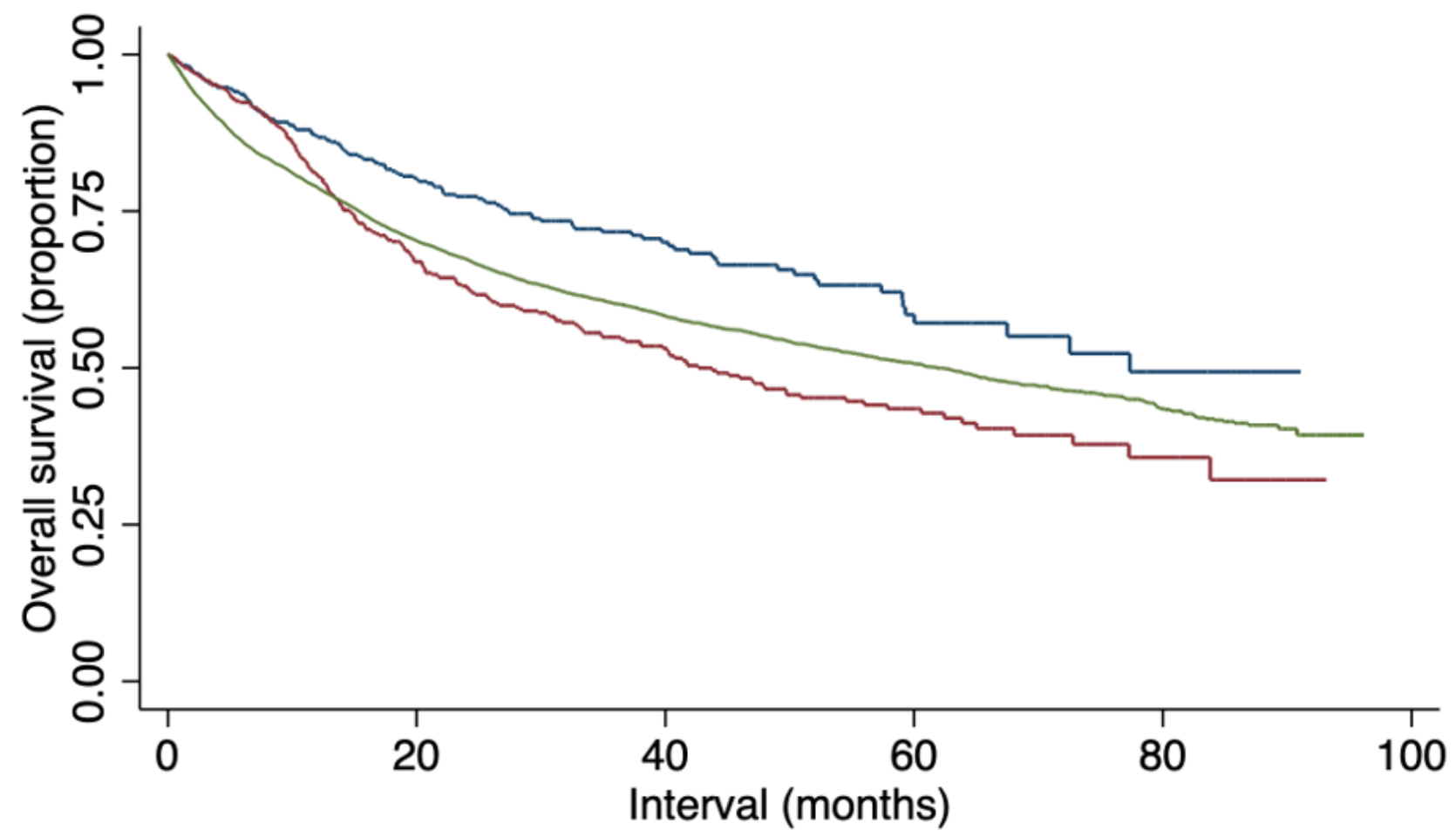

Number at risk

$\begin{array}{rccccc}\text { MGMT + 464 } & 289 & 119 & 44 & 11 & 0 \\ \text { MGMT - 476 } & 267 & 138 & 67 & 14 & 0 \\ \text { Not reported 8870 } & 5099 & 3052 & 1533 & 364 & 0\end{array}$

Figure 2

Kaplan Meier curve comparing overall survival of all patients when stratified by MGMT methylation status. 

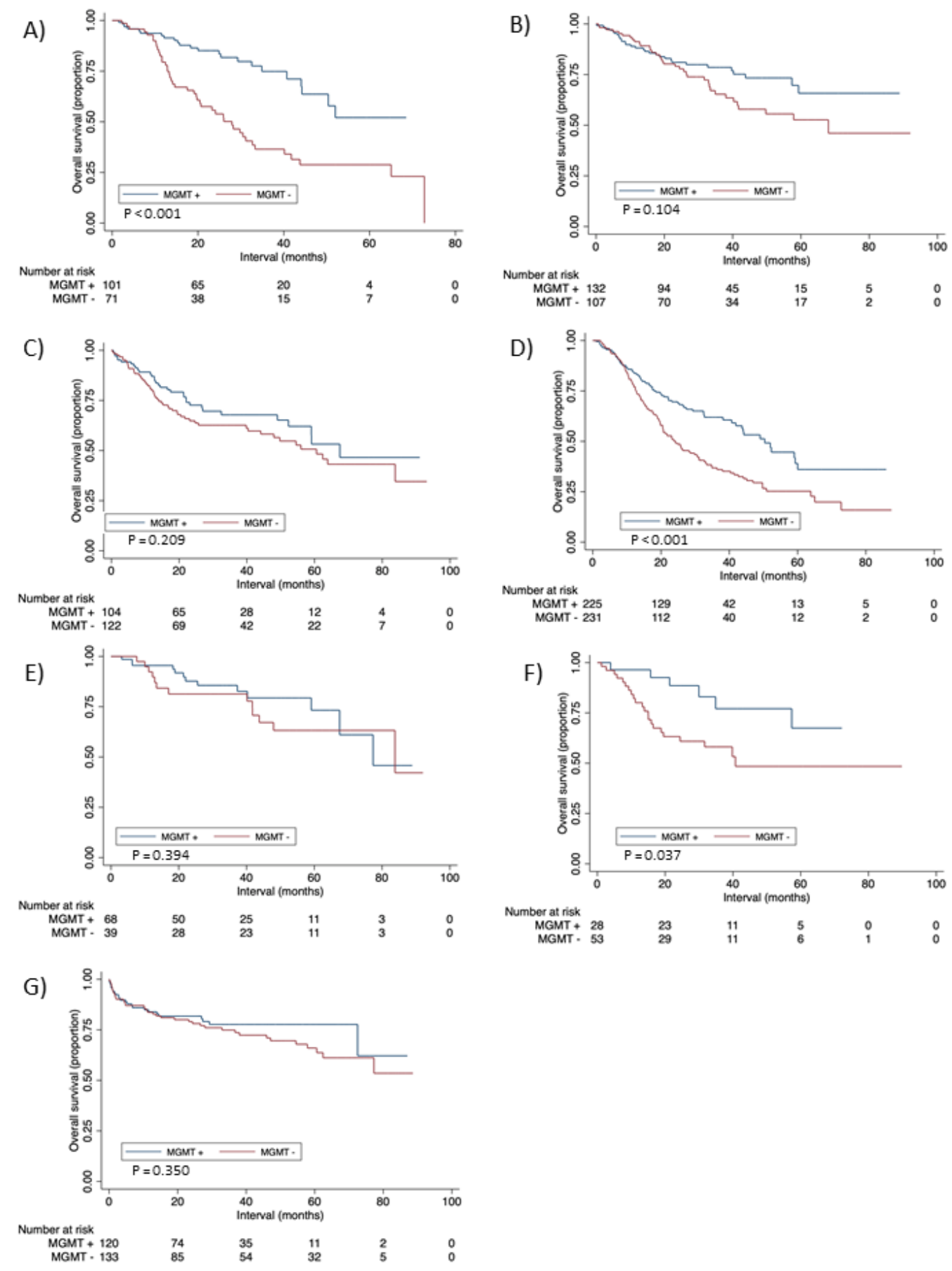

\section{Figure 3}

Kaplan Meier curve comparing overall survival for patients when stratified by MGMT Status amongst patients receiving: A) Gross total resection; B) subtotal resection; C) biopsy only; D) adjuvant chemoradiation; E) adjuvant chemotherapy; F) adjuvant radiation; and E) no adjuvant treatment. 